Supporting Information

\title{
Synthesis of a Novel Poly(binaphthylene ether) Containing Trifluoromethyl Groups with a Low Dielectric Constant
}

\author{
Kousuke Tsuchiya ${ }^{a}$, Yuji Shibasaki $^{a}$, Masahiro Aoyagi ${ }^{b}$ and Mitsuru Ueda *a $^{\mathrm{a}}$ \\ ${ }^{a}$ Department of Organic and Polymeric Materials, Graduate School of Science and \\ Engineering
}

Tokyo Institute of Technology, 2-12-1 Ookayama, Meguro-ku, Tokyo 152-8552, Japan.

Fax \& Tel: +81 35734 2127, E-mail: mueda@polymer.titech.ac.jp

${ }^{\mathrm{b}}$ National Institute of Advanced Industrial Science and Technology(AIST),

Tsukuba Central 2, 1-1-1 Umazono, Tukuba, Ibaraki, 305-8568 Japan

Fax: +81 29861 5529; Tel: +81 29862 6511; E-mail: $\underline{\text { m-aoyagi@aist.go.jp }}$ 


\section{Experimental Section}

Materials. Nitrobenzene was distilled under reduced pressure over calcium hydride and stored over 4-A molecular sieves. 4,4'-Dihydroxy-2,2'-bistrifluoromethylbiphenyl was prepared by a reported procedure. ${ }^{1 \mathrm{~S}}$ The other materials were used as received.

Preparation of monomer 1. To the solution of 4,4'-dihydroxy-2,2'-bistrifluoromethylbiphenyl (0.86 g, $2.67 \mathrm{mmol})$ in quinoline $(5 \mathrm{ml})$ and toluene $(5 \mathrm{ml})$ was added potassium carbonate $(0.83 \mathrm{~g}, 6.00 \mathrm{mmol})$, and heated at 150 ${ }^{\circ} \mathrm{C}$ for $2 \mathrm{~h}$ to remove water with a dean-stark apparatus. After the formation of the potassium salt, toluene was removed by heating at $130{ }^{\circ} \mathrm{C}$, and the solution was cooled to room temperature. To this suspension were added copper powder $(0.016 \mathrm{~g}, 0.13 \mathrm{mmol})$ and 1-bromonaphthalene $(0.75 \mathrm{~mL}, 5.3 \mathrm{mmol})$, followed by heating the mixture at $200{ }^{\circ} \mathrm{C}$ for $24 \mathrm{~h}$ under nitrogen atmosphere. After cooling this solution to room temperature, the reaction mixture was extracted with dichloromethane, and washed subsequently with a 1 $\mathrm{N} \mathrm{HCl}$ and a $3 \% \mathrm{NaOHaq}$ solutions. The solvents were evaporated, and the residual oil was purified by silica gel column chromatography (toluene/hexane 1/2 in volume ratio), and recrystallized from hexane to give a white needle-like crystals. The yield was $0.8 \mathrm{~g}$ (52\%). Mp: $204-205{ }^{\circ} \mathrm{C} . \quad{ }^{1} \mathrm{H}$ NMR $\left(\mathrm{CDCl}_{3}\right): \delta=7.08-7.12(\mathrm{~m}, 4 \mathrm{H}), 7.24(\mathrm{~d}, 2 \mathrm{H})$, 7.43-7.49 (m, 4H), 7.51-7.58 (m, 4H), $7.71(\mathrm{~d}, 2 \mathrm{H}), 7.89-7.93(\mathrm{~m}, 2 \mathrm{H})$, and 8.13-8.16 
$\operatorname{ppm}(\mathrm{m}, 2 \mathrm{H}) .{ }^{13} \mathrm{C} \mathrm{NMR}\left(\mathrm{CDCl}_{3}\right): \delta=115.2,116.2,120.0,122.3,123.9$ (q, $\mathrm{J}=274.2$ Hz), 125.0, 126.3, 126.8, 127.3, 128.4, 131.1 (q, J = 30.9 Hz), 131.6, 134.0, 135.5, 152.2, and 158.3 ppm. IR (KBr): 775 and 1315 (C-F), 1234 (C-O), 1573 and $1596(\mathrm{Ar}-\mathrm{H})$, and $3058 \mathrm{~cm}^{-1}$ (Ar-H). Anal. Calcd for $\mathrm{C}_{34} \mathrm{H}_{20} \mathrm{~F}_{6} \mathrm{O}_{2}: \mathrm{C}, 71.08 \%$; $3.51 \%$. Found: $\mathrm{C}$, $71.41 \% ; \mathrm{H}, 4.04 \%$.

Polymerization. To the solution of $\mathbf{1}(2.00 \mathrm{~g}, 3.48 \mathrm{mmol})$ in nitrobenzene (10 mL, 15 wt $\%$ ) was added $\mathrm{FeCl}_{3}(1.41 \mathrm{~g}, 8.70 \mathrm{mmol})$ under nitrogen atmosphere. The reaction mixture was stirred for $6 \mathrm{~h}$ at room temperature, and poured into methanol containing a small amount of concentrated HClaq solution. A precipitate was dissolved in toluene, filtered and reprecipitated with methanol. The precipitate was collected and dried at 200 ${ }^{\circ} \mathrm{C}$ for 1 day under the reduced pressure. The white polymer 2 was obtained. The polymer was characterized by IR, ${ }^{1} \mathrm{H}$ NMR, and ${ }^{13} \mathrm{C}$ NMR spectroscopy and elemental analysis. The yield was $1.7 \mathrm{~g}(85 \%) .{ }^{1} \mathrm{H} \mathrm{NMR}\left(\mathrm{CDCl}_{3}\right): \delta=7.22-7.60(\mathrm{~m}, 16 \mathrm{H})$ and $8.31 \mathrm{ppm}(\mathrm{s}, 2 \mathrm{H}) .{ }^{13} \mathrm{C} \mathrm{NMR}\left(\mathrm{CDCl}_{3}\right): \delta=114.1,116.7,120.5,123.9(\mathrm{q}, \mathrm{J}=272.5 \mathrm{~Hz})$, $122.5,126.8,127.2,127.3,127.5,128.4,131.3(q, J=29.7 \mathrm{~Hz}), 132.0,134.0,134.9$, 152.4, and 158.2 ppm. IR (KBr): 767 and 1315 (C-F), 1230 (C-O), 1592 and $1616 \mathrm{~cm}^{-1}$ (Ar-H). Anal. Calcd for $\mathrm{C}_{34} \mathrm{H}_{18} \mathrm{~F}_{6} \mathrm{O}_{2}: \mathrm{C}, 71.33 \% ; \mathrm{H}, 3.17 \%$. Found: C, $70.98 \%$; $3.78 \%$. 
Measurement. Infrared (IR) spectra were recorded on a Horiba FT-720

spectrophotometer. ${ }^{1} \mathrm{H}$ and ${ }^{13} \mathrm{C}$ NMR spectra were obtained on a BRUKER DPX-300 spectrometer at 300 and $75 \mathrm{MHz}$, respectively. Deuterated chloroform was used as a solvent with tetramethylsilane as an internal standard. Number- and weight-average molecular weights $\left(M_{\mathrm{n}}\right.$ and $\left.M_{\mathrm{w}}\right)$ were determined by a gel permeation chromatograph (GPC) on a Jasco GULLIVER 1500 system equipped with a polystyrene gel column (Plgel $5 \mu \mathrm{m}$ MIXED-C) eluted with chloroform at a flow rate of $1.0 \mathrm{~mL} \mathrm{~min}^{-1}$ calibrated by standard polystyrene samples. Thermal analysis was performed on a Seiko EXSTAR 6000 TG/DTA 6300 thermal analyzer at a heating rate of $10{ }^{\circ} \mathrm{C} / \mathrm{min}$ for thermogravimetry (TG) and a Seiko EXSTAR 6000 DSC 6200 at a heating rate of 10 ${ }^{\circ} \mathrm{C} / \mathrm{min}$ for differential scanning calorimetry (DSC) under nitrogen. Refractive indices $(n)$ of polymer films formed on quartz substrates were measured at a wavelength of $1320 \mathrm{~nm}$ at room temperature with a Metricon model PC-2000 prism coupler. Using linearly-polarized laser light with parallel (TE: transverse electric) and perpendicular (TM: transverse magnetic) polarization to the film plane, the in-plane $\left(n_{\mathrm{TE}}\right)$ and out-of-plane $\left(n_{\mathrm{TM}}\right)$ refractive indices and the film thickness of the samples were determined. The film was spin-coated on a silicone wafer from the polymer solution in toluene. The electrical properties were determined after vapor deposition of gold and 
aluminum with $600 \mathrm{~mm}$ diameter on the surface and back of the film by using a network analyzer (Hewlett-Packard $\square$ 4280A $1 \mathrm{MHz}$ C meter/C-V plotter). This allowed measuring the capacitance and the breakdown voltage of the films. The $\varepsilon$ value can be calculated from the capacitance using the formula $\varepsilon=c d / A \varepsilon_{0}$, where $c$ is the observed capacitance, $d$ the film thickness, $A$ the aluminum area, and $\varepsilon_{0}$ the free permittivity. The cyclic voltammogram was measured at room temperature in a typical three electrode with a working (Pt wire), a reference $(\mathrm{Ag} / \mathrm{AgCl})$, and a counter electrode (Pt spiral) under a nitrogen atmosphere at a sweeping rate of $10 \mathrm{mV} / \mathrm{s}$ (Hokuto Denko HSV-100). A $0.1 \mathrm{M}$ solution of tetrabutylammonium perchlorate (TBAP) in anhydrous acetonitrile was used as an electrolyte. 


\section{References}

(1S) Grob, M. C., Feiring, A. E., Auman, B. C., Percec, V, Zhao, M., and Hill, D. H., Macromolecules, 1996, 29, 7284. 
Figure 1S. Expanded ${ }^{1} \mathrm{H}$ NMR spectrum of monomer 1.

Figure 2S. Expanded ${ }^{13} \mathrm{C}$ NMR spectrum of monomer 1.

Figure 3S. Cyclic voltammogram of monomer 1. 


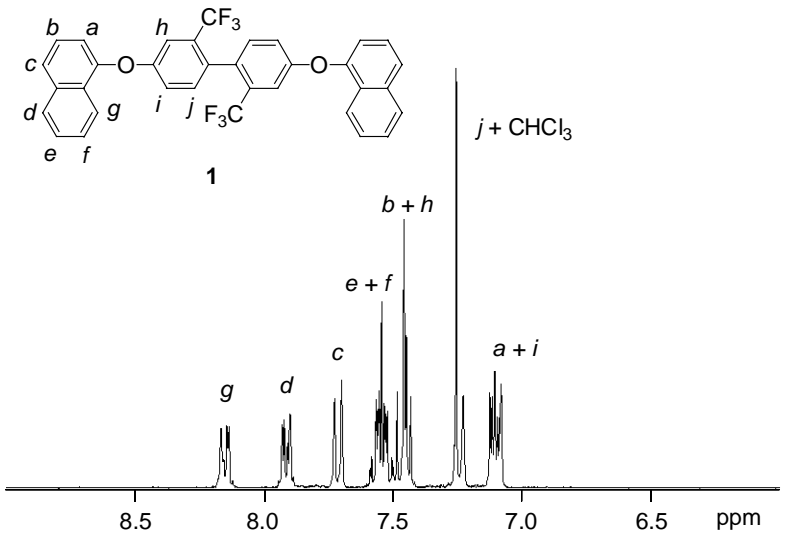

Figure 1S. K. Tsuchiya et al. 


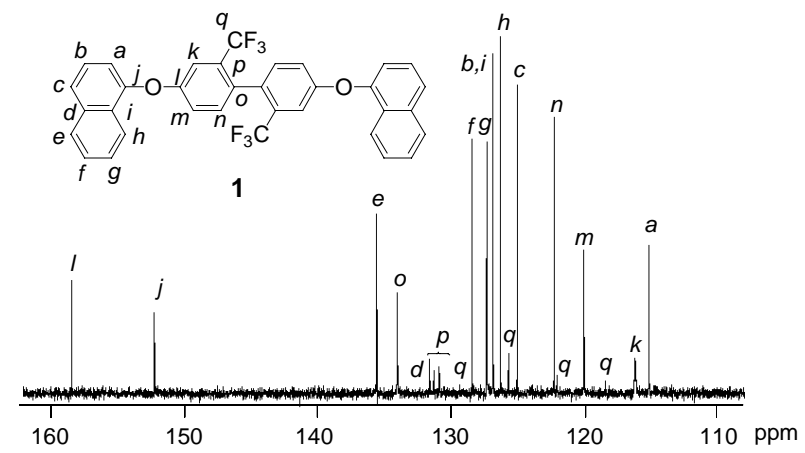

Figure 2S. K. Tsuchiya et al. 


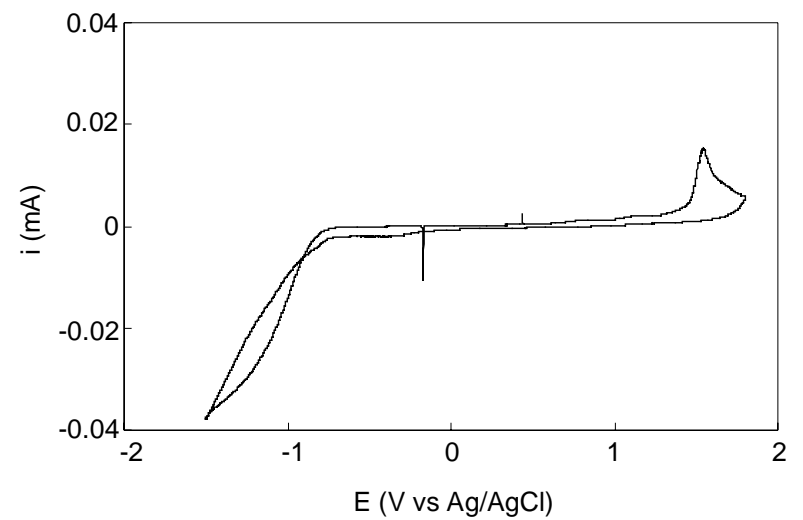

Figure 3S. K. Tsuchiya et al. 